\title{
Construction of PREMUX and preliminary experimental results, as preparation for the HCPB Breeder Unit mock-up testing
}

\author{
F. Hernández ${ }^{1, *}$, M. Kolb ${ }^{2}$, R. Annabattula ${ }^{3}$, O. Bitz ${ }^{1}$, U. Haefner ${ }^{1}$, M. Ilic $^{1}$, R. Schmidt ${ }^{1}$, A v. d. Weth
}

THE HCPB-TBM BREEDER UNIT (BU) IN ITER

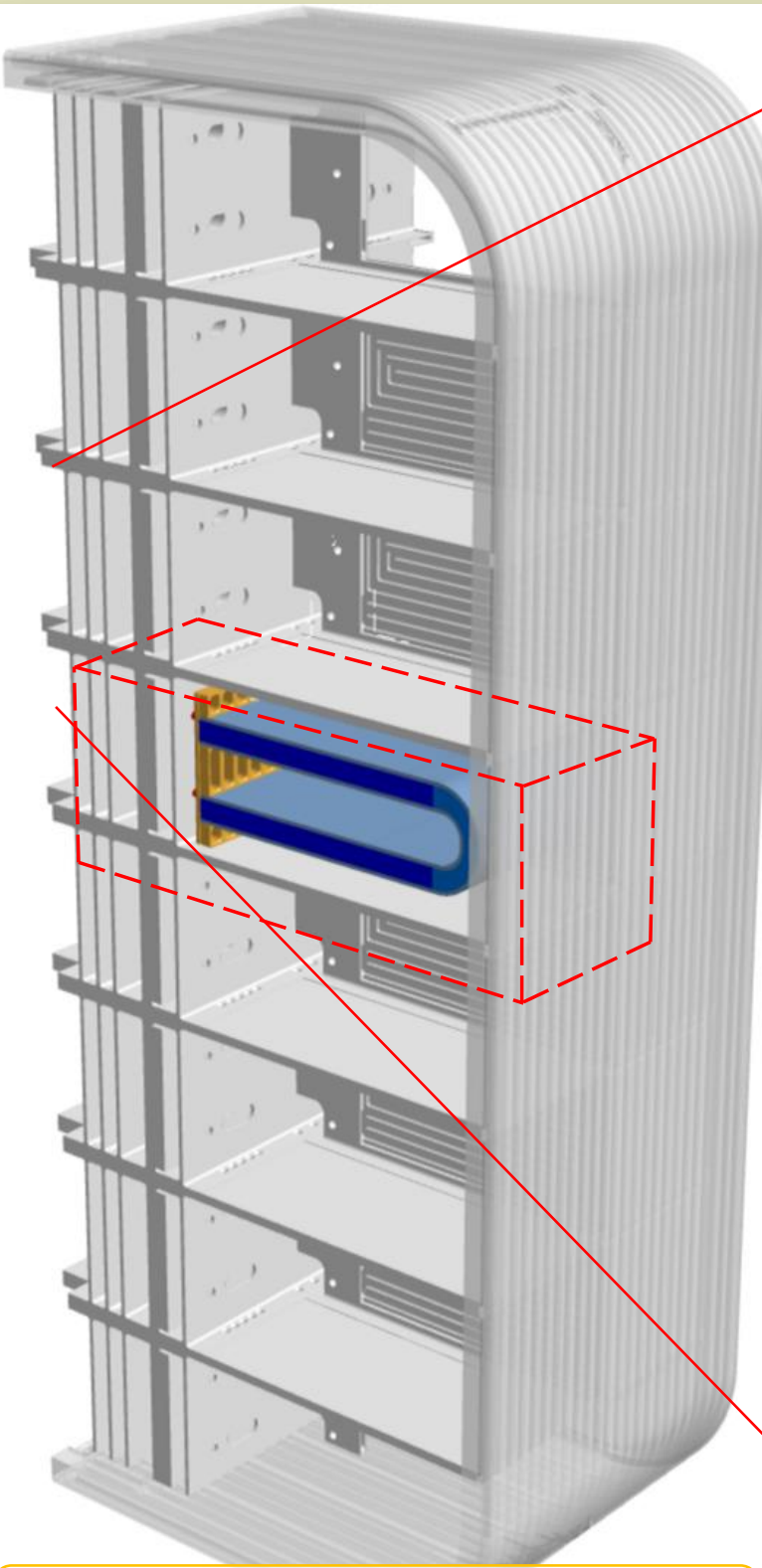

HCPB-TBM

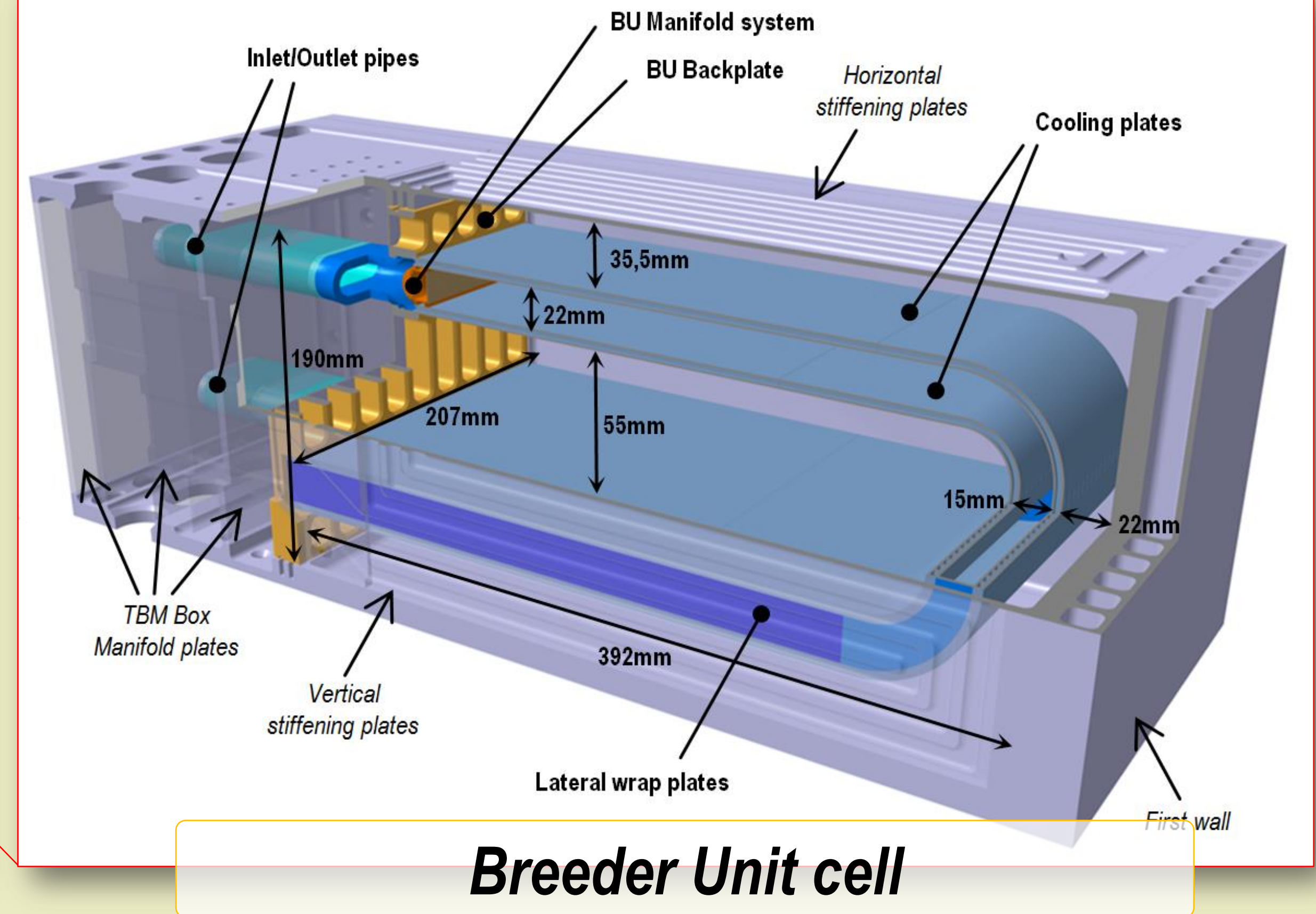

Breeder Unit cell

Mid-term goal: out-of-pile qualification of the thermo-mechanical performance of a HCPB-TBM Breeder Unit mock-up for ITER

\section{BU MOCK-UP (BU MU) CONCEPTUAL STUDIES FOR AN OUT-OF-PILE TESTING}

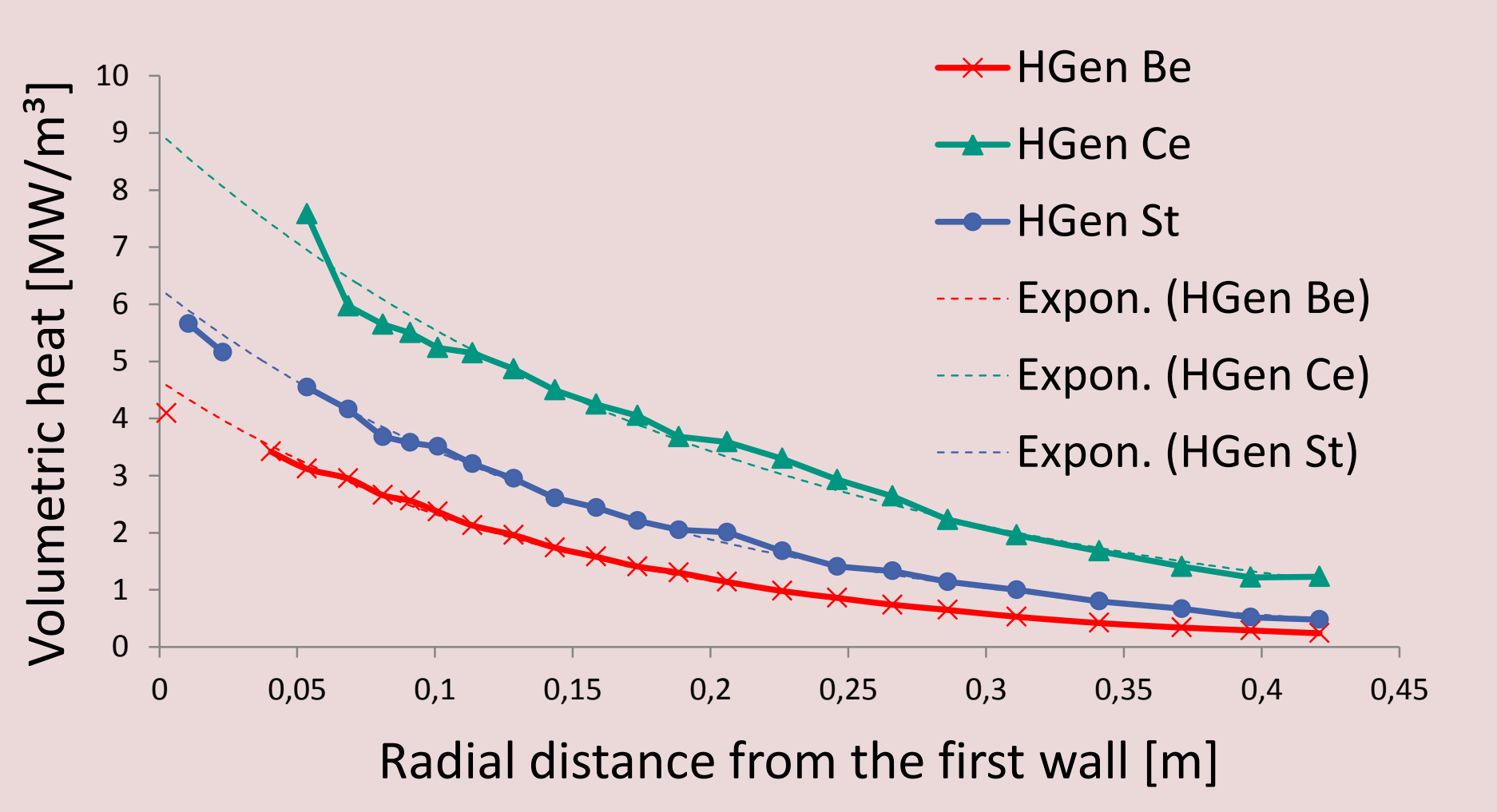

The discretization of the neutronic volumetric heat in cells of homogeneous heat is the basis for the out-of-pile BU MU concept. The idea is to insert a blocks of wire heaters in each cell that will reproduces this neutronic heat.

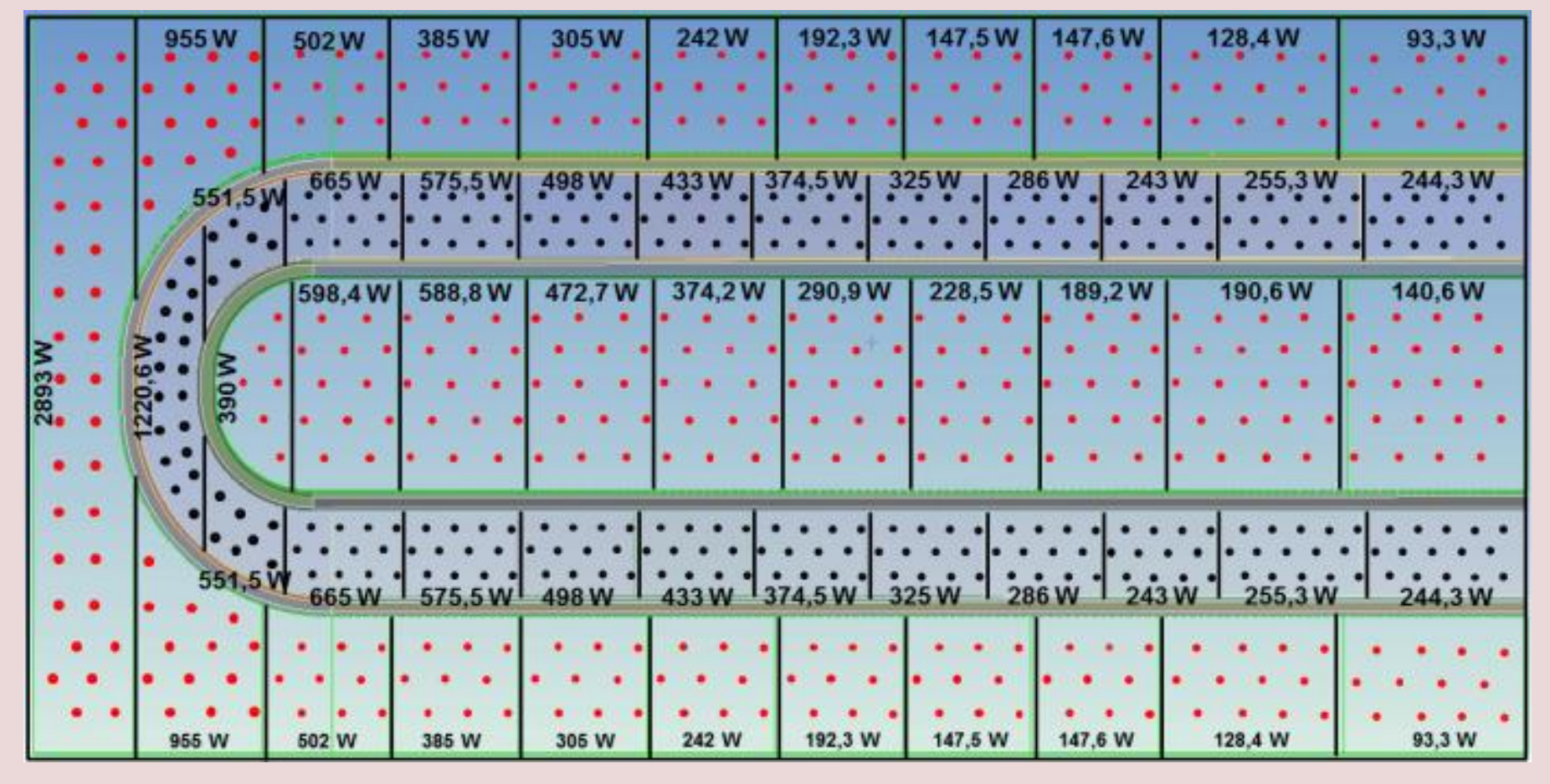

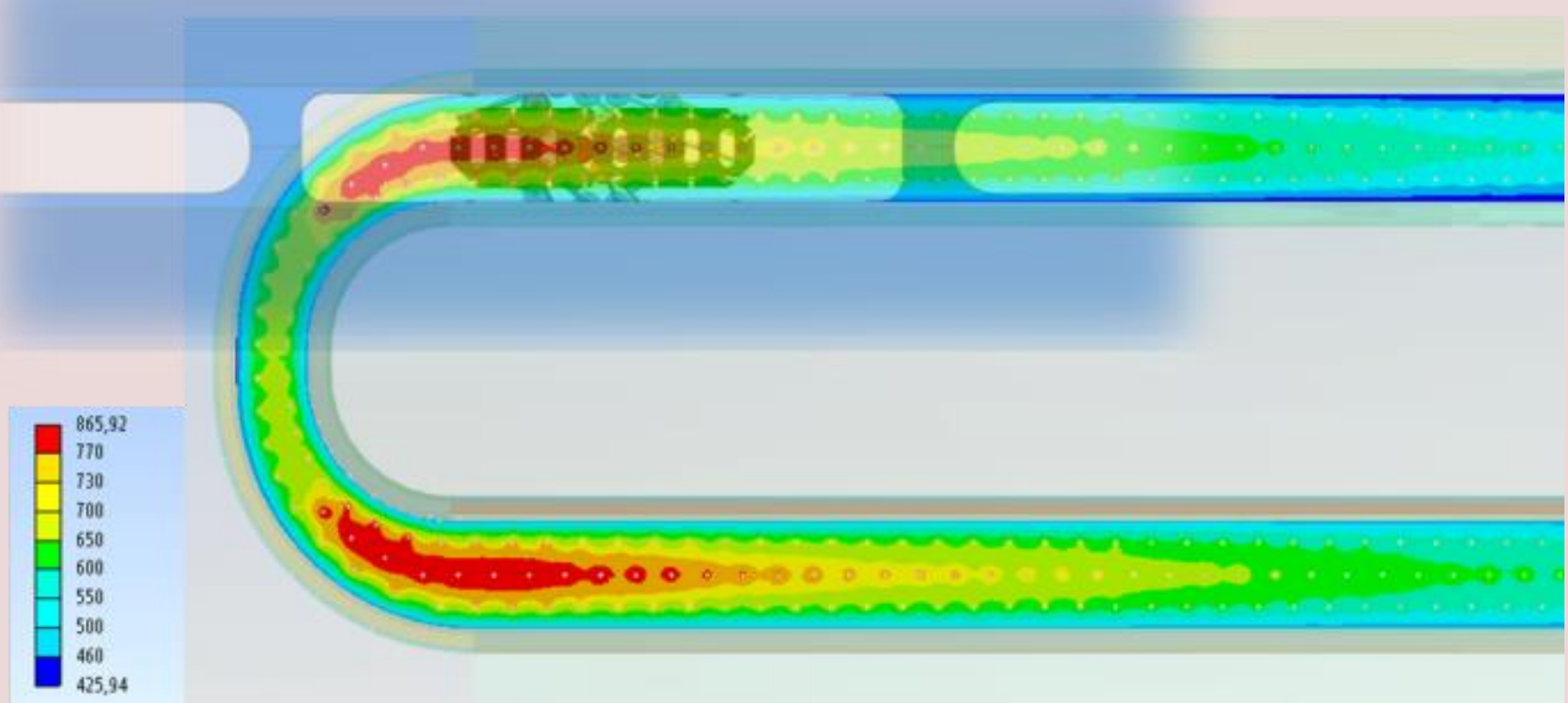

BU temperature distribution

\section{THE PREMUX DESIGN}

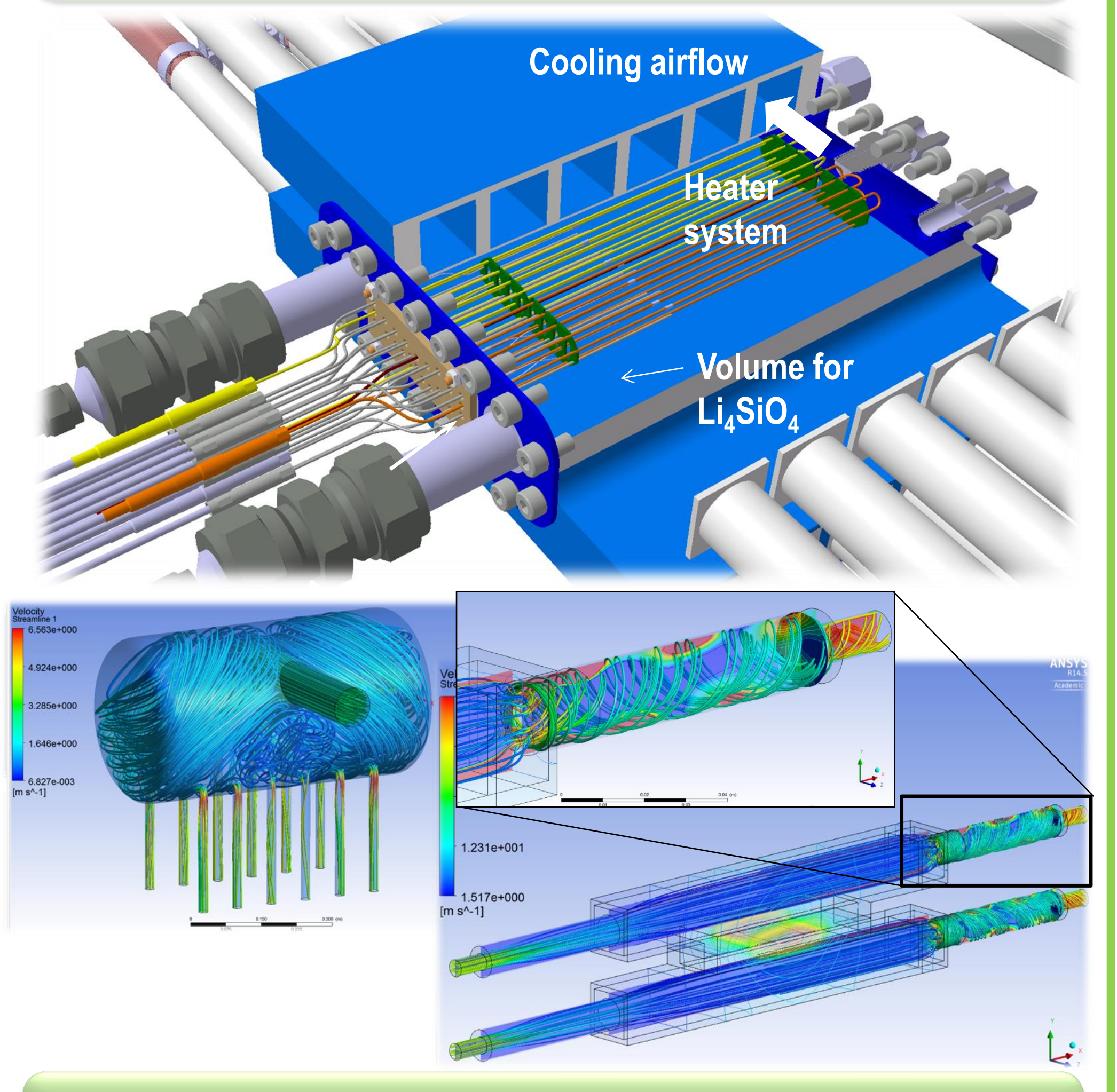

PREMUX experiments aims at testing this key concept step, reproducing a slice of the BU MU. Comprehensive studies have been done during the design of PREMUX to keep relevant conditions to a BU MU.

\section{PREMUX CONTROL TOOL AND TEMPERATURE RECONSTRUCTION}

A PREMUX Control Tool software has been developed in Labview to monitor PREMUX systems. Three panels allows the real time monitoring of: (1) $\mathrm{Li}_{4} \mathrm{SiO}_{4}$ temperature monitoring and heater control, (2) PREMUX ancillary systems monitoring, and (3) L-STAR/LL loop systems control and monitoring.
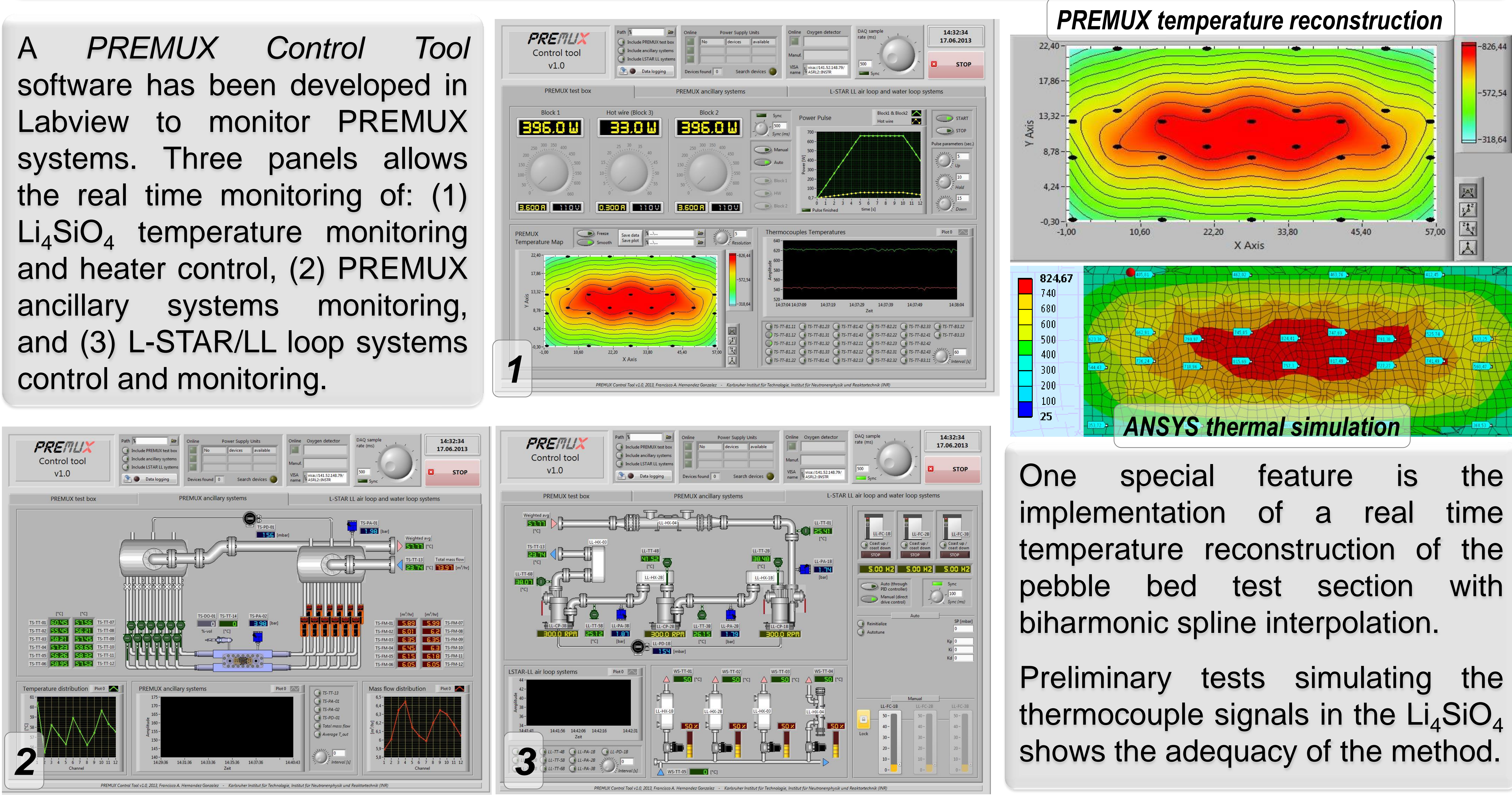

One special feature is the implementation of a real time temperature reconstruction of the pebble bed test section with biharmonic spline interpolation.

Preliminary tests simulating the thermocouple signals in the $\mathrm{Li}_{4} \mathrm{SiO}_{4}$ shows the adequacy of the method.

\section{CONSTRUCTION OF PREMUX AND TEST CAMPAIGN PLANNING}

PREMUX is integrated in L-STAR/LL Large Loop (air loop, max. 0.3 MPa, max. $660 \mathrm{~g} / \mathrm{s} 25^{\circ} \mathrm{C}$ to $390^{\circ} \mathrm{C}$ ).

PREMUX will consist in 3 series of experiments:

(1) steady state power runs, increasing the power deployed by the heaters and measuring the $\mathrm{Li}_{4} \mathrm{SiO}_{4}$ temp.

(2) runs reproducing ITER power pulses

(3) runs for determination of the pebble bed thermal conductivity by pulsed hot wire method

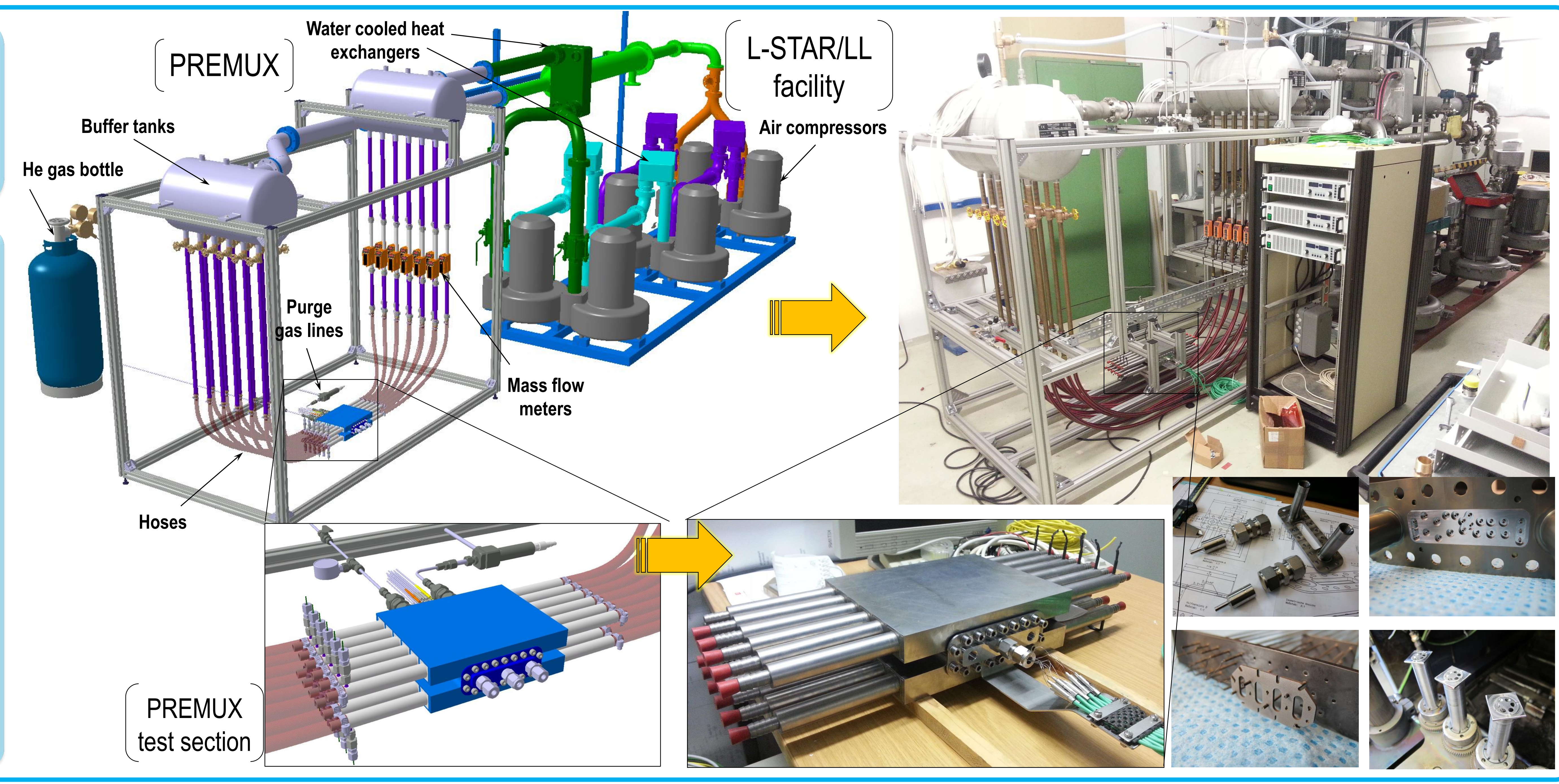

"Corresponding author. Institute for Neutron Physics und Reactor Technology, Karlsruhe Institute of Technology, Germany. E-mail: francisco.hernandez@kit.edu 